declined to attend. That was unfortunate given that the gathering was intended to discuss the principles of the Basel Declaration, which promotes outreach by animal researchers to politicians and the public. And something else failed to materialize - Germany's plans to create a professional office to promote and implement the Basel Declaration principles, which some attendees had hoped would be announced at the meeting by the country's research organizations.

This lack of action reflects poorly on Germany's proclaimed interest in creating an environment within which its generously funded biomedical research can flourish. And it is disconcerting, because, like all countries in the European Union (EU), Germany must translate into national law a complex and controversial directive that regulates the use of animals in research.

The Basel Declaration was drafted at a meeting of mostly Swiss and German scientists last November. It has now been signed by nearly 900 people, some 500 of whom came from other countries. The scientists want the declaration to have the same authority over the ethics of animal experimentation as the 1964 Declaration of Helsinki has over the ethics of human experimentation. The formal infrastructure being developed around the declaration could help to realize this ambition.

The declaration was prompted by concerns over the EU animalresearch directive, early drafts of which were so unfriendly to researchers that European scientists were shocked at how unprepared they were to lobby in the same arena as animal welfare and rights groups. Political battles raged for years before the directive was finally approved in 2010. Only one country abstained from what was otherwise a unanimous vote: Germany.

Why? Germany handed prime responsibility for the directive to the agricultural ministry. Others in the government, notably the research ministry, disagreed with this approach and the two ministries could

not agree on much right up to the vote. The agricultural ministry is now handling implementation without consultation with scientists.

Had representatives of the German government showed up at last week's meeting, as their Swiss counterparts did, they would have heard from researchers how the loose wording of much of the directive could create difficulties for them while it is being implemented, and how translate into national law a complex and controversial directive."
"Germany must

they must therefore be consulted.

For example, the directive requires that a 'severity degree' classification be introduced for all approved animal procedures. The signatories to the Basel Declaration approve of this, but some government offices in Europe have discussed whether an experiment should automatically be given a higher severity grade if it uses animals that have been genetically engineered, and whether the classifications should be made public.

German animal-welfare groups could also be part of these debates - as Swiss ones are - but they rarely communicate with the research community.

This relationship presents a challenge for German signatories to the Basel agreement and is a prime example of why Germany needs an office to coordinate the outreach the declaration calls for. The country's research funding organizations - particularly stalwarts such as the Max Planck Society, the German Research Foundation and the Helmholtz Society - need to move swiftly to create such an office.

Switzerland has dodged bullets aimed at its sturdy scientific base by animal-rights campaigners and opponents of genetic engineering in recent years, partly by maintaining excellent communication and transparency. Germany will find it even harder to bring these groups together - but even the longest journey must start with a short walk. .

\section{Scientific climate}

\section{Results confirming climate change are welcome, even when released before peer review.}

$\mathrm{G}$ lobal warming is really happening - really. There was no conspiracy or cover-up. Peer review did not fail and the scientists who have spent decades working out the best way to handle and process data turned out to know how to handle and process data after all. Thank you Berkeley Earth Surface Temperature (BEST) study.

Four papers released by the BEST team at the University of California, Berkeley, last week are of undoubted interest to the media, given that they support what is portrayed as the mainstream scientific position on climate change. They could also find traction in politics, especially in the United States, where they could be used to combat the assertions of Republicans, who have effectively tossed climate science away. But the headline scientific conclusion, that a century and a half of instrumental measurements confirm a warming trend, is, well, all a little 1990.

Of course, reproduction of existing results is a valid contribution, and the statistical methods developed by the BEST team could be useful additions to climate science. But valid contributions and useful additions alone do not generate worldwide headlines, so the massive publicity associated with the release of the papers (which were simultaneously submitted to the Journal of Geophysical Research) is a curious affair.

There was predictable grumbling at the media coverage from within the scientific community, which saw it as publicity in lieu of peer review. Reporters are more than happy to cover the story now, while it's sexy, but will they cover it later, when the results are confirmed, adjusted or corrected in accordance with a thorough vetting? The short answer is no, many of them will not. Barring an extraordinary reversal of message, the wave of press coverage is likely to be only a ripple when the papers are finally published. And this is what upsets the purists: the communication of science in this case comes before the scientific process has run its course.

Members of the Berkeley team revelled in their role as scientific renegades. Richard Muller, the physicist in charge, even told the BBC: "That is the way I practised science for decades; it was the way everyone practised it until some magazines - particularly Science and Nature - forbade it."

This is both wrong and unhelpful. It is wrong because for years Nature has explicitly endorsed the use of preprint servers and conferences as important avenues for scientific discussion ahead of submission to this journal, or other Nature titles. For example, on page 493 this week we publish a paper that discusses the dwarf planet Eris, based on results that the lead author presented (with Nature's knowledge and consent) at a conference several weeks ago. Journalists are, of course, welcome to report what they come across in such venues - as several did on Eris. What Nature discourages is authors specifically promoting their work to the media before a peer-reviewed paper is available for others in the field to read and evaluate.

Muller's statement is unhelpful because such inflammatory claims can only fuel the heated but misguided debate on climate-sceptic blogs and elsewhere about the way science works and how it treats those who insist on viewing themselves as outsiders.

To solicit input on results before publication is not a guerrilla action against a shadowy scientific elite. Witness the posting on a preprint server last month of the paper reporting neutrinos that apparently travel faster than light: the authors made it clear that they were seeking help from the wider community to explain the $\rightarrow$ NATURE.COM To comment online, click on Editorials at: go.nature.com/xhunqv findings, and the media stories (if not the headlines) mostly reflected that. To pretend otherwise can only erode public trust in science, as it is practised by all. 